\title{
From Unemployment Insurance to Employment Security : the inventible choice for the unemployment insurance reform in China
}

\author{
Ruan Xiang* \\ School of Public Administration \\ Yunnan University of Finance and Economics \\ Kunming, China \\ (xxrfrxx@163.com)
}

\begin{abstract}
The particularity of unemployment insurance has determined the co-existence of both its positive and negative impact on employment. In view of this, we must attach importance and strengthen the role it has played in promoting employment. The unemployment insurance established in the context of enterprise restructuring and structural reform no longer satisfies the demand of new situation, therefore, an employment-oriented reform is pressing. The purpose of such reform is to establish a new and complete employment security system that covers both urban and rural areas through 3 stages.
\end{abstract}

Keywords-Employment Security; Unemployment Insurance; re-employment promotion; unemployment prevention

\section{INTRODUCTION}

The particularity of the object of unemployment insurance has made its action and retroaction relation with employment or even the whole economic development more direct. For this reason, the issue concerning the impact of unemployment insurance on employment has become one of the key points for researchers both at home and abroad. Since 1970s, the appearance of economic stagflation has induced the peak for Western scholar's research on unemployment insurance system. A series of theoretical frameworks, such as the "labor-leisure theory" proposed by Moffitt and Nicholson, the "dynamic search theory" proposed by Mortensen and "implicit contract theory" proposed by Feldstein, have been formed, or even have triggered a considerable amount of empirical research, i.e. Meyer (1990) holds that unemployment insurance can have an incentive effect for an unemployed person to find a work that has high return and high technology content, which helps to increase his or her income after he or she is reemployed, however, this inevitably causes ethical risk. ${ }^{[1]}$ After 2000, many domestic scholars also start to focus on the impact of China's unemployment insurance on employment and their studies are mainly concentrated on the several aspects as listed below: Firstly, it is the effect of existing system in promoting employment. Secondly, it is about how to improve the existing system. Most of the scholars hold that we should establish an employment-oriented unemployment insurance system. Lv Xuejing, Professor of Renmin University of China, has proposed that the strategic target of the development and reform of China's unemployment insurance system is to establish an employment security system that takes the urbanrural overall development into consideration and aims at promoting employment, and has also put forward a three-step development strategy including the improvement of 3 large functions of unemployment insurance system, the basic completion of an employment security system that takes the urban-rural overall development into consideration and realizes the sustainable development of employment security system. ${ }^{[2]}$ Thirdly, it is to draw on experiences from the reform of foreign unemployment insurance system. The target and core of the reforms in most countries have been shifted from negative livelihood security to active promotion of employment.

On the basis of drawing on the achievements of above studies, by analyzing the inevitability of the reform of China's unemployment insurance system, this paper puts forward a comprehensive reform target which is to build an employment security system, and in detail, it has also proposed the specific steps and measures of the reform.

\section{BODY}

\section{A. The 30 years of Development for China's Unemployment Insurance: the Co-existence of Achievements and Problems}

\section{1) Developments and Achievements}

China's unemployment insurance system was initially founded in 1986 and the Promulgation of the Regulation on Unemployment Insurance in 1999 marks the basic formation of the system. Throughout almost 30 years of development, in general, the unemployment insurance system has been developing fast, which has become an important program in China's social security system and the achievements obtained are mainly shown in the followings: Firstly, in the critical period during the reform of state-owned enterprises and the reform of economic system, unemployment insurance, as the supportive measures of the reform, provides basic livelihood for the laid-off people and effectively maintains the social 
stability during transitional period. Secondly, China subsidizes measures facilitating the re-employment, such as job intermediary and vocational training and promotes the establishment and development of labor market. Thirdly, it is to align the system mode with the international standard. Among countries and territories that have established unemployment security systems, nearly $80 \%$ of them adopt or mainly adopt compulsory social insurance as China did. [3] Statistical data has shown that 15 years from 1999 to 2014 , the number of people in the country who have bought unemployment insurance has increased from 98.52 million to 170.43 million with approximately an annual growth rate of $4 \%$. The scale of income and expense for the fund has also increased respectively from 15.22 billion and 9.16 billion in 1999 to 103.8 billion and 61.5 billion in 2014 .

\section{2) Existing Problems}

Firstly, it is the small coverage, low benefit and substitution rates and insufficient livelihood security. In comparison against the working population in urban cities in the corresponding period, from 1999 to 2014, the coverage rate of unemployment insurance is always around $40 \%$, however, the figure would be only around $20 \%$ if it was against the whole working population. In the registered urban unemployed population, the share of people who are entitled to the treatment of unemployment insurance is basically no higher than $60 \%$. Whereas among the unemployed people, those who can actually enjoy the treatment of unemployment insurance is even lower. High risk groups, such as the college and university graduates, rural migrant workers and people without fixed employment, have been excluded from the system. In terms of the security level, the monthly average level of payment for the country in 2014 is 852 yuan, which only accounts for $20.46 \%$ of the average wage in the society and $35.45 \%$ of the per capita disposable income of the country's urban residents.

Secondly, the efficiency in using the fund is low with excessive surplus .From 1999 to 2014, the surplus of unemployment insurance fund has increased from 15.99 billion to 445.1 billion, which is 27 times of increase. The appearance of huge amount of surplus has seriously violated such "collectpay principle" applied in the fund. The role the unemployment insurance should have in promoting employment is not being played sufficiently and basically, its function in preventing unemployment and stabilizing employment is absent.

Thirdly, it is the unreasonableness for the design and management of certain rules. In terms of the design of fee collection, overall, the rate is high. Also the unified rate lacks flexibility and motivation. In terms of the expense design, the mode and level of payment for unemployment insurance are not in compliance with the international standard, there is little condition for such payment and the payment is being offered for a long time. There is no fixed proportion, standard and operation method for the payment given in promoting employment. In terms of the management of such system, the overall planning level of the fund is low with decentralized management and weak regional coordination.

\section{B. Inevitable Direction of the Reform: Employment Promotion}

\section{1) Active Security Conforms to the New and Sustainable Development Target of International Social Security}

Though the new liberalism thought has impact on the global-wide reform of social security, the new development concept for social security which has been gradually formed through reflection and reform indeed benefits the long term healthy development of social security system more. The reform characterized by an employment oriented unemployment insurance system can well be considered as the reflection of the new healthy development concept. First of all, instead of focusing on the livelihood of those unemployed, it will help them to get reemployed. Secondly, it changes the content of insurance from relief to prevention and remedy, and stresses on the prevention and intervention before the occurrence of risk. Thirdly, it has also stressed the division of governmental and individual responsibilities within the system. The active job-seeking behaviors conducted by the unemployed individual will be more closely related to the treatment he or she may acquire, which will reflect more about the corresponding relation between rights and obligations.

\section{2) The New Employment Situation Demands the System to Play a Larger Role in Employment}

At very beginning when China's unemployment insurance was first established, it was mainly targeted at a large number of laid-off workers that has caused during the transformation of enterprises. However, over nearly 30 years of development, the economy and social environment when the system was enacted has changed greatly since then. First of all, the slow down in domestic economic development, the adjusting and upgrading of industrial structure, overall severe employment situation and prominent structural contradictions has demanded the unemployment insurance to play an even larger role in promoting employment. Secondly, the diversified employment has also caused a diversified unemployed population. In particular, the old unemployed group, dominated by laid-off workers of enterprises coexists with those new unemployed group, represented by college and university graduates and rural migrant workers. Therefore, in order to play a larger securing role, the unemployment insurance must cover those new unemployment group having even younger age and proactively help them to realize employment is far more important than negatively insuring their livelihood. Thirdly, It is even more necessary to organically combine the treatment of unemployment insurance with measures promoting employment, in this way, not only this can fully bring the adjusting effect the unemployment insurance on business cycle, but also avoid rigid growth in spent on securing basic livelihood.

\section{3) Experience of Other Countries has Laid the Foundation for Comprehensive Reform}

As an important content of the reform of social security system, the shift from negative livelihood security to active promotion of employment has become the common view and 
general practice of a number of major market economy countries, including the US, Germany, the UK and France. Japan, Canada and Korea has even established an "unemployment insurance" that focuses more on employment promotion and unemployment prevention. Japan's employment insurance system is a typical case, it has established three undertakings aimed at preventing unemployment and promoting employment, namely the employment security undertaking, capability development undertaking and employment welfare undertaking. Each of them has implemented many meticulous and detail measures. ${ }^{[4]}$ It is of great reference value for China' unemployment insurance reform. Chinese government has also enacted sporadic adjustment policy over recent years, which can be considered as pilot projects and explorations for a comprehensive reform.

\section{The Aim of the Reform: from Unemployment Insurance to Employment Security}

Based on above analysis, it is not only necessary, but is also pressing for us to carry out a reform of Chinese unemployment insurance system, which is aimed at promoting employment. However, this reform should not only be an adjustment for the detail of the existing unemployment insurance policy, rather, we should establish a new employment security system that is complete and covers both rural and urban area. The specific content of the reform are the followings:

\section{1) First Stage: the Adjustment and Improvement of Unemployment Insurance}

The first stage task of the reform is to adjust and modify the content of existing unemployment insurance, complete its traditional function of ensuring basic livelihood, strengthen the existing measures that promote employment and establish a more incentive premium collection and mode of treatment payment, hence to lay foundation for the further expansion of its security function.

First of all, expand the coverage of unemployment insurance. 3 groups of people should be included. First of all, it is the public servants, which can further narrow the gap in terms of social security policy between public servants and enterprise personnel. Secondly, it is the inclusion of college and university graduates. In short term, we can consider the establishment of a relatively independent unemployment insurance system for college and undergraduate students first, which can be incorporated into the unified unemployment insurance once it is basically developed to be mature. We can adopt the principle of compulsory insurance coverage, in which the premium will be jointly collected by the college or university students themselves, schools and governments. The content of security should high light the employment orientation, thus can be considered as the experimental field in testing the function of unemployment insurance in promoting employment. [5] Thirdly, rural migrant workers and people without fixed employment should be included and thus establish a fund collection and appropriation method that corresponds with its characteristics.
Secondly, it is to establish a more incentive fee collection method. We should change the existing unified rate into differential rate and to set up enterprise rates of different level based on the unemployment conditions of different industries. In addition, we can further use the floating insurance rate as a means to restrain the arbitrary termination acts conducted enterprises. By the time the employment promotion and unemployment prevention measures have been fully implemented, we can divide the fee paid into employment insurance fee and employment promotion fee, wherein the employment premium will be shared by enterprises and individuals, and the employment promotion fee adopts differential rate and floating rate. ${ }^{[6]}$

Thirdly, it is to grant a more reasonable treatment to ensure basic livelihood. Firstly, we should change the treatment calculation method and correlates it with one's salary before unemployment, which not only reflects the principle that the right is relevant to obligation, but also conforms to the international mainstream practice. Secondly, it is the moderate improvement of the overall treatment level, but should not exceed $50 \%$ of the salary before unemployment and must decrease along with the time. Thirdly, shorten the period to grant treatment, which firstly can be reduced from 24 months at present to 18 months, and shortened to 12 months by the time the condition is mature.

Fourthly, it is to Specify the percent of fund that is used for employment promotion function. Set forth the specific operation for the provision of subsidy for vocational training and intermediaries and closely connect it with the grant of unemployment insurance benefit. Strictly identify those who do not comply with the preset conditions. ${ }^{[7]}$

\section{2) Second Stage: from Unemployment Insurance to Employment Insurance}

The second stage task of the reform is to further improve the employment promotion function, supplement and improve its unemployment prevention function, upgrade the unemployment insurance with complete integration of three functions to employment insurance.

Firstly, it is to gradually improve the level of overall planning for unemployment insurance. Based on China's actual conditions, the target of improving the level of overall planning is to realize the overall planning at the provincial level. Establishing a nation-wide unemployment insurance adjusting fund and such fund is formed by collecting in certain proportion from all provinces, autonomous regions and municipalities. When the unemployment insurance fund in a certain overall planning area can not make the ends meet, the country shall first appropriate such adjusting fund to supplement it, and then it may be additionally subsidized by local finance.

Secondly, it is to establish the employment stabilizing system and to supplement the function of unemployment insurance in preventing unemployment. This system can be consisted of the followings: for those enterprises who take measures, such as reducing working hours and lowering down salaries, thus to share posts instead of laying off workers, they can be granted with salary subsidies for a certain period. Also 
social insurance subsidies will be given to enterprises that hire groups of people who have difficulties to get employed. Moreover, training subsidies will be given to those who take the initiative in organizing vocational training rather than laying off employees. ${ }^{[8]}$

Thirdly, it is to increase reemployment incentive measures and further strengthen their role in promoting employment, i.e. salary subsidies may be grant to those reemployed people (who remain unemployed for a long period of time) with salary lower than a certain standard. Youth internship subsidy will be given to those employing units who provide internship position to young people or college or university students who are employed for the first time. Training subsidy will be given to those unemployed people who take part in vocational training. For those unemployed people who intend to start their own business, they are allowed to receive unemployment insurance benefit that has not enjoyed as the startup capital or alternatively, or to enjoy the subsidized loan or guarantee provided by the unemployment insurance fund.

\section{3) Third Stage: from Employment Insurance to Employment Security}

The third stage task is to connect those basically matured systems of employment insurance to the emergency unemployment assistance and unemployment aid, hence to construct a comprehensive employment security system that coordinates the development of urban and rural areas

Firstly, it is to establish an unemployment insurance emergency mechanism to deal with any nation-wide or regional major event that has caused an obvious increase of the number of unemployed people. Specific contents should include the provision of subsidies for job subsidy, social insurance subsidy and entrepreneurship subsidy; for social enterprises, allow them to delay their payment of social insurance and and job subsidy to them; for regions, offer training subsidy, tax reduction and provide guarantee for small amount loan. ${ }^{[9]}$

Secondly, it is to establish the system connection between employment insurance and unemployment aid. For those whose basic livelihood still can not be ensured due to special reasons, i.e. illness, disaster, family reason or those who can not enjoy unemployment benefits or those unemployed in difficulties but has exceeded the limited period for such benefits can enjoy unemployment aid. However, we must be careful that there should be a specific condition for one to enjoy such aid and its standard must be greatly different to the general unemployment benefits.

Thirdly, we should ensure that the unemployment insurance cover all the laborers from both rural and urban areas. Establish a complete employment service information platform and employment service network, in this way, the archives management and follow-up service aimed at those unemployed can be realized. Further integrate employment security with those positive and employment promoting policies contained in the Employment Promotion Act.

\section{CONCLUSION}

Along with the change of economic situation both at home and abroad, China is facing an increasingly severe unemployment problem. Therefore, the unemployment insurance should play a more positive and comprehensive security effect. This paper has analyzed the status quo of the implementation of current unemployment insurance. It has proposed its policy view on the steps and measures for the construction of an all-round employment security system. It is believed that in the near future, an employment security system that ensures the livelihood, prevents unemployment and facilitates employment will play an even larger role in promoting continuous and healthy development of social economy.

\section{ACKNOWLEDGMENT}

This paper has absorbed the thoughts of many previous research results, from which it has obtained many guidance and enlightenments, particularly the chief writer of Chapter VIII of The Strategy of Social Security Reform in China: General Introduction, Professor Lv Xuejing. In Addition, I should also thank all the classmates of the School of Public Administration, Yunnan University of Finance and Economics for their long term support and help offered to my study.

\section{REFERENCES}

[1] Meyer, B., Unemployment Insurance and Unemployment Spells[J], Econometrica, 1990, 58 (4) : 757-782

[2] Zheng Gongcheng - The Strategy of Social Security Reform in China: General Introduction [M], Beijing: People's Press, 2011, 344-378.

[3] Ruan Xiang - Reform and Development of the Unemployment Insurance in Foreign Countries [J], China Labor, 2008 (4), 30-31.

[4] Shi jingfang - Japanese Unemployment Eecurity System Construction and Its Revelation [J],Journal of Northeast University of Finance and Economics, 2011(6),65-70

[5] Ruan Xiang - Preliminary Discussion of the Design of Unemployment Insurance System for College and University Students [J], Finance \& Economy, 2015 (12), 89-91.

[6] Zheng Gongcheng - The Strategy of Social Security Reform in China: General Introduction [M], Beijing: People's Press, 2011, 369-370.

[7] Li dayou, Zhang rongfang - From Unemployment Insurance to ployment Insurance : the New Path of the Unemployment Insurance Reform in China[J],Journal of South-Central University for Nationalities (Humanities and Social Sciences), 2011(3),110-111

[8] Zheng Gongcheng - The Strategy of Social Security Reform in China: General Introduction [M], Beijing: People's Press, 2011, 365-366.

[9] Zheng Gongcheng - The Strategy of Social Security Reform in China: General Introduction [M], Beijing: People's Press, 2011, 364-365. 